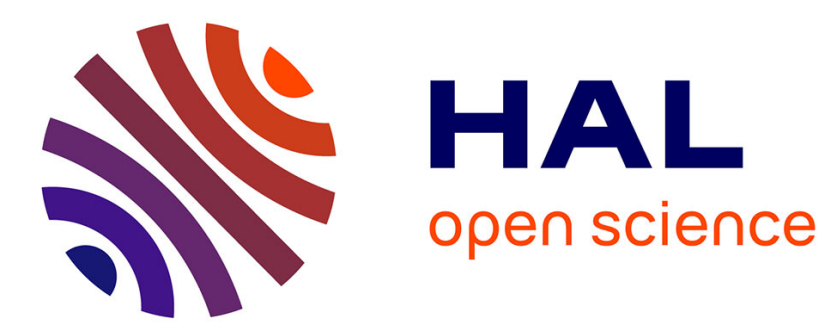

\title{
Adaptation and the Easterlin Paradox
}

Andrew E. Clark

\section{To cite this version:}

Andrew E. Clark. Adaptation and the Easterlin Paradox. 2015. halshs-01112725

\section{HAL Id: halshs-01112725 \\ https://shs.hal.science/halshs-01112725}

Preprint submitted on 3 Feb 2015

HAL is a multi-disciplinary open access archive for the deposit and dissemination of scientific research documents, whether they are published or not. The documents may come from teaching and research institutions in France or abroad, or from public or private research centers.
L'archive ouverte pluridisciplinaire HAL, est destinée au dépôt et à la diffusion de documents scientifiques de niveau recherche, publiés ou non, émanant des établissements d'enseignement et de recherche français ou étrangers, des laboratoires publics ou privés. 


\title{
PARISSCHOOL OF ECONOMICS
}

WORKING PAPER Nº $2015-05$

Adaptation and the Easterlin Paradox

\author{
Andrew E. Clark
}

JEL Codes: I31, D60

Keywords: Easterlin Paradox, Income, Adaptation

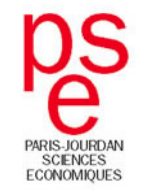

PARIS-JOURDAN SCIENCES ECONOMIQUES

48, BD JOURDAN - E.N.S. - 75014 PARIS

TÉL. : 33(0) 143136300 - FAX: 33 (0) 143136310 


\title{
Adaptation and the Easterlin Paradox*
}

\author{
Andrew E. Clark ${ }^{1}$ (Paris School of Economics-CNRS)
}

January 2015

\begin{abstract}
Two behavioural explanations of the Easterlin Paradox are commonly advanced. The first appeals to social comparisons, whereby individual $i$ compares her income $\left(\mathrm{Y}_{\mathrm{it}}\right)$ to a comparison income level earned by some other individual or group $j\left(\mathrm{Y}^{*}{ }_{\mathrm{jt}}\right)$. The second explanation is that of adaptation to higher levels of income. This is of the same nature, but here the individual's current income is compared to her own income in the past (i.e. $\mathrm{Y}_{\text {it }}$ is compared to $\mathrm{Y}_{\mathrm{it}-\tau}$, for some positive value or values of $\tau$ ). The first of these explanations has attracted far more empirical attention than has the second. This is probably for dataavailability reasons, as the investigation of the latter requires panel information. There is also a suspicion that large changes in $\mathrm{Y}_{\mathrm{it}}$ might be accompanied by a movement in some other variable that is also correlated with subjective well-being. We here review the empirical evidence that individuals do indeed compare current to past income, and then whether individuals adapt in general to aspects of their economic and social life. Last, we ask whether adaptation is in fact a viable explanation of the Easterlin Paradox.
\end{abstract}

Keywords: Easterlin Paradox, Income, Adaptation.

JEL Classification Codes: I31, D60.

\footnotetext{
* I am grateful to Paul Frijters, Rich Lucas, Ewen McKinnon, Robert Rudolf, Aki Tsuchiya and seminar participants at the Comparative Study of Happiness Conferences in Kyoto and Paris for useful comments.

1 PSE, 48 Boulevard Jourdan, 75014 Paris, France; Andrew.Clark@ens.fr.
} 


\section{Introduction}

The Easterlin paradox has captured a great deal of attention across social science. The fundamental question behind this paradox is whether income is associated with subjective well-being, where the latter is often measured by single-item questions on happiness or life satisfaction. The broad consensus that has been reached is that, within country, richer people are on average happier than poorer people, and that richer countries are on general happier than poorer countries. As such, the cross-section relationship between income and subjective well-being is positive.

But looking at cross-sections, of individuals within a country or of countries, is not the only way to address this central question. The second approach appeals to time-series data to see what happens to average well-being as countries become richer. The rather disconcerting answer here is that over time rising average income does not seem to go hand-in-hand with higher happiness. This is the Easterlin paradox: money does bring happiness in the crosssection, but not in time series.

Easterlin's time-series analyses have been replicated a number of times (some recent flat happiness time series in growing countries appear in Clark et al., 2014b), although other work has suggested a positive time-series correlation between per capita GDP and average subjective well-being in at least some countries (see Stevenson and Wolfers, 2008).

There are two common behavioural explanations of the Easterlin Paradox (as discussed at length in Clark et al., 2008). The first is social comparisons, whereby individual $i$ compares her income $\mathrm{Y}_{\mathrm{it}}$ to a comparison income level earned by some other individual or group $j\left(\mathrm{Y}^{*}{ }_{\mathrm{jt}}\right)$. The second explanation is that of adaptation to higher levels of income. This is of the same nature as the first, in the sense that it relies on comparisons, but here the individual's current income is compared to her own income in the past (i.e. $\mathrm{Y}_{\mathrm{it}}$ is compared to $\mathrm{Y}_{\mathrm{it}-\tau}$, for some positive value or values of $\tau$ ).

It is probably true to say that overall the first of these explanations has attracted far more empirical attention than has the second. This is likely for data-availability reasons, as the comparison of my current income to its past levels requires panel data on the same individual. There may also be a suspicion that large changes in $Y_{i t}$ are sometimes accompanied by a movement in some other variable that is also correlated with subjective well-being. 
This paper will concentrate on the second explanation of the Easterlin Paradox, and will review the empirical evidence that individuals do indeed compare current to past income. It then asks whether adaptation in subjective well-being is a general phenomenon, in the sense that we eventually get used to all changes, with respect to the labour market, marriage, children, health and so on. It concludes by going back to the beginning and asking under which conditions adaptation to rising income is in fact a viable explanation of the Easterlin Paradox. By doing so, it will underline areas where our knowledge is lacking despite the remarkable growth in work on well-being over the past two decades.

\section{Adaptation to Income}

Adaptation to anything boils down to a comparison of your current situation with what you have experienced in the past. Higher past levels of a certain experience may partly offset current levels of the same experience, due to changing expectations (Kahneman and Tversky, 1979), so that evaluations of situations depend on changes relative to a reference situation, rather than absolute magnitudes. ${ }^{2}$ As suggested above, adaptation belongs to the realm of comparisons in the well-being or utility function.

If it is income that is being compared, then we can replace our standard well-being function, $\mathrm{WB}=\mathrm{W}(\mathrm{Y}, \ldots)$, with $\mathrm{WB}=\mathrm{W}\left(\mathrm{Y}, \mathrm{Y}^{*}, \ldots.\right)$. The variable $\mathrm{Y}^{*}$ in this expression is what is commonly-called "comparison income": the income to which we compare/the income of the reference group. We suppose that $\mathrm{W}_{1}>0$, as is standard, but that $\mathrm{W}_{2}<0$ : as reference income rises, my well-being falls. It is of interest to compare the size of the two marginal effects. If $\mathrm{W}_{1}+\mathrm{W}_{2}=0$, then a rise in own income and comparison income of the same amount has no effect on well-being.

As intimated in the Introduction, we can compare to a variety of different reference groups. In the above equation, $\mathrm{Y}^{*}$ may refer to the income of other people who look like me (with the same age, sex, education etc.), others in the same household (including the individual's partner), friends, neighbours, work colleagues and so on. One of the issues in the current empirical literature is that we do not really know which of these reference groups are salient,

\footnotetext{
2 "an object at a given temperature may be experienced as hot or cold to the touch depending on the temperature to which one has adapted. The same principle applies to non-sensory attributes such as health, prestige and wealth" (Kahneman and Tversky, 1979, p. 277).
} 
so that the measure of $\mathrm{Y}^{*}$ we impose may be far from the correct one. ${ }^{3}$

Adaptation arguably suffers less from this drawback, as each individual only has one past: in that sense, the reference group is well-defined (being myself in the past). Empirically, the analysis of adaptation in subjective well-being proceeds by the introduction of lagged values of the variable in question into the well-being function above. Very often, one-year lags are used (almost all panels are annual) so that we have $\mathrm{WB}=\mathrm{W}\left(\mathrm{Y}, \mathrm{Y}_{\mathrm{i}, \mathrm{t}-1}, \ldots.\right)$. If we compare to ourselves in the past, then we will have, as above, $\mathrm{W}_{1}>0$ and $\mathrm{W}_{2}<0$. If it is thought that adaptation acts over a longer duration than one year, then further lags will be introduced.

If we adapt to income, then we imagine that a rise in income increases subjective well-being when it happens, but that after some time we become used to it. In the case of the one-year lag above, we would estimate an equation of the form:

$\varphi \mathrm{WB}_{\mathrm{it}}=\underline{\beta}^{\prime} \underline{X}_{\mathrm{it}}+\varphi_{0} \mathrm{Y}_{\mathrm{it}}+\varphi_{1} \mathrm{Y}_{\mathrm{it}-1}+\varepsilon_{\mathrm{it}}$

The coefficient on current income, $\varphi_{0}$, is thought to be positive: income is positively correlated with well-being. The coefficient $\varphi_{1}$ reveals the presence of adaptation to income.

Imagine the case of an initial stable income level of $\bar{Y}$ followed by a permanent income rise of $\Delta \mathrm{Y}$. In this case, we have the following.

i) The year before the income rise, year 1 say, well-being is given by $\underline{\beta}^{\prime} \underline{X}_{\mathrm{it}-1}+\varphi_{0} \bar{Y}+$ $\varphi_{1} \bar{Y}$.

ii) The year the income rise happens, year 2, well-being is $\underline{\beta}^{\prime} \underline{\mathrm{X}}_{\mathrm{it}}+\varphi_{0}(\bar{Y}+\Delta \mathrm{Y})+\varphi_{1} \bar{Y}$.

iii) The year afterwards, well-being is $\underline{\beta}{ }^{\prime} \underline{X}_{i t+1}+\varphi_{0}(\bar{Y}+\Delta \mathrm{Y})+\varphi_{1}(\bar{Y}+\Delta \mathrm{Y})$.

Imagine, for simplicity, that the $\underline{X}$ 's do not change over time. It is obvious that $\mathrm{WB}_{\mathrm{i} 2}$ is greater than $\mathrm{WB}_{\mathrm{i} 1}$, as $\varphi_{0}$ is positive. But what happens in year 3? The difference in well-being between years 2 and 3 is given by $\varphi_{1} \Delta \mathrm{Y}$. If $\varphi_{1}$ is negative, then well-being falls back again from years 2 to 3 : in other words there is adaptation. And if $\varphi_{0}+\varphi_{1}=0$, then well-being falls

\footnotetext{
${ }^{3}$ The third wave of the European Social Survey is one of very few surveys which actually ask respondents about income comparisons. Respondents first answer how important it was for them to compare their income with other people's incomes, and then whose income they would be most likely to compare their own with. The answers to the latter question were work colleagues, family members, friends, or others. Clark and Senik (2010) show that the majority of those who compare their incomes compare them to the income of their work colleagues.
} 
back to its year-1 level, despite the fact that income is now higher. This latter is the case of full adaptation, where any stable income level is as good as any other stable income level. Here income brings about higher well-being only in the short-run (in this example, in year 2), but the effect totally dissipates by year 3 .

The comparison of the size of $\varphi_{0}+\varphi_{1}$ in the example above therefore reveals the extent of adaptation:

- If $\varphi_{1}=0$, then there is no adaptation to income;

- If $\varphi_{1}<0$ and $\left|\varphi_{0}\right|>\left|\varphi_{1}\right|$, then there is partial adaptation to income (over the time period under consideration); and

- If $\varphi_{1}<0$ and $\left|\varphi_{0}\right|=\left|\varphi_{1}\right|$, then there is full adaptation to income (over the time period under consideration).

Under full adaptation, higher income will raise well-being when it is received, but after some time individuals will become used to this higher income, with subjective well-being returning to its pre- income-rise level. Figure 1 illustrates such a case where the short-run benefit of higher income disappears in a linear fashion over the following three years. The top line refers to happiness and the lower line income. There is a jump in income at the beginning of year two, which remains thereafter at this higher level. Happiness also jumps when income rises, but due to adaptation happiness returns to its initial level by the beginning of year five.

The level of well-being to which individuals return after adaptation is often called the individual set-point. With a constant value of the variables in $\underline{X}$ above, this set-point would be given by $\underline{\beta} \underline{X}_{i}$; as such, it differs between individuals. ${ }^{4}$ The literature on adaptation to various states can also be couched in terms of whether the individual's set-point has changed following the event (as in Lucas et al., 2004).

The remainder of this section will consider the evidence we have that individuals do indeed compare their income to that which they have received in the past. Despite the obvious importance of the question, there is perhaps less empirical work on adaptation to income than might be imagined. An early contribution is Brickman et al. (1978), who conclude that a small sample of lottery winners $(n=22)$ are not significantly more satisfied with their lives

\footnotetext{
${ }^{4}$ If we believe that there is full adaptation to income, then none of the variables in the $\underline{X}$ vector should be determined by the individual's financial situation.
} 
than are a control group. ${ }^{5}$

Inglehart and Rabier (1986) use an explicit measure of the change in income, which they relate to life satisfaction. In pooled Eurobarometer data from ten Western European countries between 1973 and 1983 subjective well-being scores are uncorrelated with current income, but positively correlated with a measure of the individual's change in financial position over the past twelve months.

In the same tradition, Clark (1999) uses the first two waves of British Household Panel Survey (BHPS) data, the panel aspect of which allows the actual changes in income from one year to the next to be calculated. The dependent variable in the empirical analysis is the job satisfaction ${ }^{6}$ of workers who stay in the same firm from one year to the next, and have stayed in the same position (i.e. have not been promoted). In the regression analysis, the income that the individual earned last year attracts a negative coefficient in the job satisfaction equation, which is consistent with adaptation. The estimated coefficients on past and current income are equal and opposite in sign, suggesting full adaptation to labour income within one year. Burchardt (2005) finds evidence of adaptation to income, using a measure of income satisfaction in ten years of BHPS data, with a suggestion of greater adaptation to rises in income than to falls in income. Other authors have used German Socio-Economic Panel (SOEP) panel data to come to similar conclusions: see Bartolini et al. (2013), Grund and Sliwka (2007), Weinzierl (2005) and Vendrik (2013). Wunder (2009) appeals to SOEP data from 1985 to 2006 to estimate that all of the improvement in the financial situation in Germany over that period was entirely mopped up by adaptation to material well-being, which he calls "desensitisation to the hedonic effects of income". A recent detailed study of life satisfaction and income adaptation appears in Di Tella et al. (2010), who analyse longitudinal data for around 8,000 individuals drawn from the West German sample of the SOEP over the period 1984 to 2000. They find that the effect of an income increase after four years is only about $42 \%$ of the effect after one year: the majority of the short-term effect of

\footnotetext{
${ }^{5}$ The data here are cross-section, so we do not know if the lottery winners were happier than the control group before their winnings. The results show that the life satisfaction of winners is higher than that of non-winners, but not significantly so. One question is whether the difference would have been significant with a somewhat larger sample size. Recent work on the BHPS using panel data has certainly suggested a significant rise in wellbeing upon winning even relatively small sums on the lottery (Apouey and Clark, 2015, and Gardner and Oswald, 2007).

${ }^{6}$ Life satisfaction did not appear in the BHPS until Wave 6.
} 
income vanishes over time. ${ }^{7}$

There are a number of "non-happiness" ways of looking for evidence of adaptation to income. The Leyden Group (see the review in Van Praag and Frijters, 1999) considered the Welfare Function of Income, in which individuals are asked to assign income levels (per period) to a number of different verbal labels (such as "excellent", "good", "sufficient" and "bad"). These answers can then be used to estimate, for each individual $i$, a lognormal "Welfare Function of Income", with estimated mean $\mu_{\mathrm{i}}$ and variance $\sigma_{\mathrm{i}}$. These two latter values can then be used as dependent variables in regressions, showing which types of individuals require a higher level of income to be satisfied, and which individuals have valuations that are more sensitive to changes in income.

The Welfare Function of Income questions have appeared in the SOEP, in the EUROSTAT surveys of the 1980s, in Russian panels, and the Dutch Socio-Economic Panel, amongst others. With respect to the topic of the current chapter, the key finding is that $\mu_{\mathrm{i}}$ is positively and significantly correlated with the individual's past income. This is what Van Praag (1971) calls "preference drift": the more that you earned in the past, the more that you need today in order to be satisfied. The findings of the Leyden group on European data suggest that about $60 \%$ of an increase in household income is dissipated within about two years via a rise in what people consider to be "excellent", "sufficient", "bad" etc. levels of income. The dissipation here is around the same order of magnitude as that found in subjective well-being panel survey data in Di Tella et al. (2010).

Last, it is of course possible to try to establish income adaptation using revealed preference information on observed behaviour, either in an experimental setting or by the use of survey data, as in Hotz et al. (1988). ${ }^{8}$

There is then a variety of evidence which is consistent with partial, or even total, adaptation to higher income. If there is indeed full adaptation, then increasing income will not have any long-run effect on subjective well-being in the long run (at least in the rich countries, from

\footnotetext{
${ }^{7}$ The same kind of analysis can also be carried out at the aggregate level. Di Tella et al. (2003) consider individual happiness in data from 12 European countries over 18 years, and argue that some of their results regarding the relationship of subjective well-being to GDP per capita show that "bursts of GDP produce temporarily higher happiness" (p.817).

${ }^{8}$ The preference for rising income profiles, given a total amount of income to be disbursed over a given period, is also consistent with adaptation to income: if past income acts as a deflator for current well-being then we would want to back-load it over time. See the hypothetical-choice results in Frank and Hutchens (1993) and Loewenstein and Sicherman (1991).
} 
which this empirical evidence is taken).

\section{Adaptation to Economic and Social Life}

The policy implication from adaptation to income is that money does not serve to increase happiness in the long-run: we therefore need to concentrate on some other aspect of life if we wish to raise societal well-being. A number of suggestions have been made along these lines: see for example the Big Seven on page 63 of Layard (2005). These fall broadly into the areas of the labour market (and having a job), marriage and the family, health, social activities, freedom, and religion.

We can of course make a good a priori case that all of these matter to individuals. However, following on from the results with respect to income in Section 2 above, might we not find adaptation in some of these aspects of life too? For example, do we adapt to marriage, and is unemployment less harmful for well-being after two years than it was at six months? This section will review what we know about adaptation to the non-pecuniary domains of life.

The analysis of adaptation in panel data follows the same individuals before, during and after their entry into unemployment (for example): this allows us to look for evidence of adaptation to the state of being unemployed. The empirical method used in many (but not all) papers is to use a within-subject (fixed-effect) approach to examine how life events affect subjective wellbeing both before (anticipation) and after (adaptation) the event in question takes place, providing the individual does not experience another change in status. This boils down to tracing out adaptation to marriage, for those who become married and stay married, for example. This way we avoid any sharp subsequent movements in well-being associated with the end of the marriage spell. It would probably sound rather odd, for example, to say that individuals have adapted to marriage by separating or divorcing.

It is worth emphasising that work on adaptation is very much ongoing, with different datasets, samples, and modelling techniques. Not all of the results of the analyses agree with each other, and it is clear for the moment that there we have not necessarily converged to the "right" answer.

The analysis of BHPS data in Clark and Georgellis (2013) uses the approach described above to model both anticipation and adaptation to unemployment, for example, at the same time 
using the following regression:

$$
\begin{aligned}
& \mathrm{WB}_{\mathrm{it}}=\alpha_{\mathrm{i}}+\underline{\beta} \underline{X}^{\prime} \underline{\mathrm{it}}_{\mathrm{it}}+\theta_{-4} \mathrm{U}_{-4, \mathrm{it}}+\theta_{-3} \mathrm{U}_{-3, \mathrm{it}}+\theta_{-2} \mathrm{U}_{-2, \mathrm{it}}+\theta_{-1} \mathrm{U}_{-1, \mathrm{it}}+\theta_{0} \mathrm{U}_{0 \mathrm{it}}+\theta_{1} \mathrm{U}_{1 \mathrm{it}}+\theta_{2} \mathrm{U}_{2 \mathrm{it}}+\theta_{3} \mathrm{U}_{3 \mathrm{it}}+ \\
& \theta_{4} \mathrm{U}_{4 \mathrm{it}}+\theta_{5} \mathrm{U}_{5 \mathrm{it}}+\varepsilon_{\mathrm{it}}
\end{aligned}
$$

Here, WB refers to individual well-being, and $\underline{X}$ is a vector of standard controls. To pick up adaption, the unemployed are split up into six groups: those who have been unemployed 0-1 years, 1-2 years, 2-3 years, and so on up to the last group who have been unemployed five years or more. These unemployment duration dummy variables are thus mutually exclusive: any unemployed individual will only be present in one of the six groups at any given year. ${ }^{9}$

If there is no adaptation to unemployment, $\theta_{0}$ through $\theta_{5}$ will be roughly the same size; if there is adaptation the later values of $\theta$ will be less negative - we will observe individuals "bouncing back" from unemployment; and with full adaptation some of the later values of $\theta$ will be insignificant. Equation (2) includes an individual fixed effect, $\alpha_{\mathrm{i}}$. Adaptation is thus tested for by comparing the well-being of those who have been unemployed for 1-2 years, for example, to the scores of the same individuals in their first year of unemployment. This seems a natural way to empirically model adaptation.

Anticipation is treated similarly in the same equation. The $U$ dummies referring to future entry $\left(U_{-4, \text { it }}\right.$ to $\left.U_{-1, i t}\right)$ show whether the individual will enter unemployment in the next $0-1$ years, 1-2 years, 2-3 years, or 3-4 years. The omitted category in equation (2) is thus those who will not enter unemployment in the next four years, and the estimation sample consists of all those individuals who are not unemployed in the first year that they are observed in the BHPS (so that they are at risk of unemployment entry).

Figure 2 below illustrates the results of this kind of analysis for five life events (unemployment, marriage, divorce, birth of child, and widowhood) in the BHPS data from Clark and Georgellis (2013). We will now consider a number of these different life events in turn.

\footnotetext{
${ }^{9}$ Which is different from the continuous variable set-up in equation (1), where individuals have both an income level now and an income level last year (i.e. they will have positive values for both $\mathrm{Y}_{\mathrm{it}}$ and $\mathrm{Y}_{\mathrm{it}-1}$ ).
} 


\subsection{The labour market}

The relationship between unemployment and subjective well-being has occupied a central place in the Economics of Happiness, with many contributions finding sharply lower wellbeing amongst the unemployed (for example, Clark and Oswald, 1994, and Winkelmann and Winkelmann, 1998). It seems beyond dispute that unemployment does indeed cause unhappiness (with broadly the same correlation being found in cross-section and panel data). However, this tells us nothing about the time profile of well-being after entry into unemployment. The three profiles in Figure 3 are all consistent with the unemployed reporting lower well-being than the employed on average, but with very divergent conclusions regarding adaptation.

The findings in Clark et al. (2008) find no adaptation to unemployment for men (with a somewhat noisier set of results for women). Both of these analyses appeal to SOEP data. Identical results are found in data from the BHPS (Clark and Georgellis, 2013), Russian Longitudinal Monitoring Survey (RLMS: Clark and Uglanova, 2012), the Korean Labor and Income Panel Study (KLIPS) for men (there are insufficient data points for women to reach a conclusion) in Rudolf and Kang (2015), and the Household, Income and Labour Dynamics in Australia (HILDA) survey in Frijters et al. (2011). The research in Lucas et al. (2004) suggests only partial adaptation to unemployment in SOEP data, as do those on Swiss Household Panel (SHP) survey in Anusic et al. (2014), although the statistical methods used there are different from those used many of the above-cited articles. ${ }^{10}$

\subsection{Marriage and the Family}

The same method as used for unemployment can be applied to family events. One of the central questions here is whether marriage makes people happy. While it is mostly obvious in cross-section data that the married are happier than the single, Stutzer and Frey (2006) suggested that most of this correlation was down to people who were happy when single being more likely to marry in the first place. Work on adaptation to marriage has suggested

\footnotetext{
${ }^{10}$ For example, Oesch and Lipps (2013) suggest that there is no evidence of adaptation to unemployment in either SOEP or SHP data. It would be useful to have a thorough discussion between economists and psychologists (and others) about the different ways in which we can model the time profile of well-being in panel data.
} 
broadly complete adaptation to marriage in the SOEP (Clark et al., 2008, and Lucas et al., 2003), BHPS (Clark and Georgellis, 2013), HILDA (Frijters et al., 2011) and SHP (Anusic et al., 2014). Adaptation here is full, or even over-full, in the sense that individuals after marriage may end up being less happy than they were when they were single (even though most work finds a positive "impact" effect of marriage on subjective well-being). ${ }^{11}$

There are, however, some country differences here in this respect. Marriage leads to lasting life satisfaction gains in Russia (Clark and Uglanova, 2012), and Rudolf and Kang (2015) also find that marriage is lastingly good in Korea (but only for men). It is also striking that in these two countries we do not observe much of a happiness spike at the year of marriage, which we do see in the other panel datasets under consideration.

The flip-side of marriage is separation and divorce. The empirical analysis of panel data here shows a sharp impact effect of divorce. Divorce is one of the events for which we also observe significantly lower subjective well-being in the years leading up to the event. This is understandable in this context, where divorce is often preceded by a number of years of separation or dysfunctional marriage. Adaptation to divorce is complete in the SOEP, BHPS ${ }^{12}$ and HILDA. The work in Anusic et al. (2014) however suggests only partial adaptation to divorce in Switzerland. In a striking mirror image of their finding of no adaptation to marriage for Korean men, the analysis in Rudolf and Kang (2015) reveals full adaptation to divorce for Korean women, but no adaptation at all for Korean men.

Some couples do not end in divorce or separation, but in widowhood. This is one of the events for which we find the largest impact effect (for example, about one point on the zero to ten scale in the SOEP). Even here, most analyses suggest that this sharp fall in well-being is not permanent, with full adaptation in British, Russian and German panel data and for Korean men, and partial adaptation in Switzerland. The outliers here are Frijters et al. (2011), who find no adaptation to the death of a spouse or child in Australian data (although they do not analyse widowhood as an isolated event), and the Korean women in Rudolf and Kang (2015).

\footnotetext{
${ }^{11}$ This work on adaptation compares subjective well-being after marriage to well-being before marriage (as in equation (2)). It is likely that well-being was on an upward profile before marriage, and it can be argued that the anticipation effects a year or more before marriage is part of marriage's well-being benefits. In that case we would maybe want to compare well-being after marriage to well-being three, four or even five years before marriage. This naturally produces less adaptation than comparing to all years before marriage. Qari (2014) adopts this technique and finds only partial adaptation to marriage in SOEP data.

${ }^{12}$ See also Blekesaune (2008) and Laporte and Windmeijer (2005) for partnership separation and the time profile of subjective well-being in BHPS data.
} 
Last, we can look at the effect of children on subjective well-being. ${ }^{13}$ Here there is consensus in the literature: the results from all of the panel datasets that we have mentioned here suggest no lasting effect of children on subjective well-being, although many of them do pick up a positive anticipation effect in the years leading up to childbirth. ${ }^{14}$

\subsection{Health}

Some work in this domain has considered adaptation to disability. Oswald and Powdthavee (2008) use BHPS data to track individuals' levels of reported life satisfaction in the years leading up to, and following, disability. Their fixed-effects regressions suggest that about onethird to one-half of the negative impact of disability on well-being dissipates over time. Lucas (2007) analyses the BHPS and SOEP data, and finds only little evidence of adaptation. Oswald and Powdthavee (2008) suggest that this difference in results may be due to the different estimation methods used, as they use fixed-effect regression analysis, while Lucas' results are based on multi-level methods. Again, the distinction between the two would seem worthy of future analysis. Anusic et al. (2014) find partial adaptation to disability in SHP data, and Frijters et al. (2011) partial adaptation to illness or injury in HILDA data.

$\mathrm{Wu}$ (2001) considers health adaptation via what is arguably quite an exogenous event: heart attacks. He shows that the onset of a new heart condition amongst individuals who have had such a condition in the past has smaller self-assessed health and emotional health effects than amongst those who have no previous heart conditions. Riis et al. (2005) uncover evidence of adaptation to hemodialysis.

Graham et al. (2011) suggest that individuals seem better able to adapt to one-off health shocks, such as the loss in mobility, than to conditions associated with uncertainty, such as anxiety and pain. However, their analysis is based on cross-section data, and they do not have both pre- and post health shock measures of subjective well-being.

An interesting mirror to most of the work in this area, which has dealt with health problems of

\footnotetext{
${ }^{13}$ Rudolf and Kang (2015) note that much of the childbirth effect found in the literature might actually reflect an overlapping effect from marriage. The joint modeling of multiple adaptation to different events seems potentially rather complicated.

${ }^{14}$ Myrskyla and Margolis (2014) find full adaptation to birth of first child in the SOEP and BHPS, although they do find less adaptation for older parents (those aged between 35 and 49 at the time of childbirth). Dyrdal and Lucas (2013) find similar adaptation profiles for both parents in SOEP data.
} 
some kind, is provided in Barazzetta (2014), who looks at adaptation to increased mobility. Her data here come from a randomised-control trial of individuals in Uganda who were fitted with orthotics designed to improve their mobility (the controls here were a wait-time group who would have the same orthotics fitted in the future). While she does indeed find that orthotics improve mobility, the well-being effects associated with this health improvement disappear after one year. This work is both unusual in that it looks at a health improvement, and that the allocation into the experimental and control groups was random, producing exogenous health changes.

Last, a separate literature has considered the well-being impact of something that is most definitely endogenous: cosmetic surgery. This is shown to have a positive impact effect on subjective wellbeing, which is long-lasting in some cases (Cole et al., 1994, and Margraf et al., 2013).

\subsection{Adaptation in Other Life Domains}

With economists' interest in the labour market, some work has considered adaptation to labour-market phenomena other than labour income and unemployment. Hanglberger and Merz (2011) appeal to SOEP data to look at adaptation to self-employment, finding full adaptation within three years, and there is full adaptation to unionization within a few years in Powdthavee (2011). On the contrary, Burchell (2011) finds that there is little adaptation to job insecurity in BHPS data (which perhaps resonates with the suggestion in Graham et al., 2011, that is difficult to adapt to conditions that are associated with uncertainty).

Outside of the labour market, there is adaptation to moving house in both the BHPS (Nowok et al., 2013) and HILDA (Frijters et al. 2011). The results in Flèche (2014) are consistent with reduced local-government autonomy in Switzerland having only temporary effects on residents' well-being. Verhaest and Omey (2009) analyse the relation between objective overeducation and job satisfaction data in a sample of Flemish school leavers. Their fixed-effects estimation results reveal a sizeable negative effect of over-education on job satisfaction. However, this effect is also shown to fall with years of work experience. In a very general approach, Frijters et al. (2014) consider the dynamics of subjective well-being in British cohort data, and conclude that individuals in general adapt to the shocks that they receive within four years. 
Last, the research discussed in Section 3 suggested that individuals adapted to income in general, by showing that past income entered a well-being regression with a negative coefficient. However, the work discussed there mostly did not distinguish between rising and falling incomes. And more importantly, it considered all movements in income, regardless of whether they occurred to richer or poorer people. However, we may be especially interested in the well-being effects of particularly low income, i.e. poverty.

Clark et al. (2014a) consider individuals as being in poverty if they live in a household whose equivalised income is under $60 \%$ of the median level of household equivalised income in the country (this is the EU definition of poverty). In SOEP data, poverty entry is associated with a sharp downward movement in life satisfaction. There is no evidence that this negative effect becomes smaller as the time spent in poverty increases. So to this extent, the effect of poverty on subjective well-being is very similar to that of unemployment: there is a large drop in life satisfaction upon entry which does not diminish over time, so that individuals do not adapt.

The combination of the result of no adaptation to poverty with that in Section 3 of broad adaptation to changes in income (which are most often income rises, at least in nominal terms) then suggests that we cannot configure the Easterlin Paradox backwards to say that recessions don't matter: while we may adapt to higher incomes, it looks as though the negative effects of particularly low income might be much more long-lasting.

The broad conclusion from the empirical results in this section is that there is adaptation in economic and social life, but that individuals take longer to become used to some states than to others. This seems in particular to apply to negative events (unemployment, poverty, disability), so that we might almost conclude as to the presence of loss-aversion in adaptation. $^{15}$

\section{Outstanding Issues}

This last substantive section considers a number of outstanding issues, and also returns to the beginning of the paper by asking whether adaptation to income does indeed represent a viable explanation of the Easterlin Paradox.

\footnotetext{
${ }^{15}$ Lyubomirsky (2011) suggests that in general adaptation is faster to positive than to negative events.
} 


\subsection{Method and Measure}

As mentioned in Section 3.1 above, there is no one universally-applied method for the analysis of adaptation in the social sciences. Broadly it seems as if economists have relied on fixed-effect estimation, whereas sociologists and psychologists have preferred multi-level methods. The former trace out adaptation in a non-parametric way, whereas multi-level methods are at least partly parametric. There is also the issue of which sample we should use to analyse adaptation, whether to drop observations when individuals exit the state in question (does adaptation to divorce include remarriage?), and what to do about repeated entries into the state in question (on which see Luhmann and Eid, 2009). A definitive answer to the question of adaptation would require some conformity in these dimensions.

A second point is what measure should be used to pick up subjective well-being. This is a vexed question: see Clark (2015). In terms of adaptation, a small number of papers have made empirical contributions to the debate by carrying out comparative analyses using more than one different well-being measure. In Clark and Georgellis (2013), the adaptation profile in the BHPS is similar for life satisfaction and the twelve-item General Health Questionnaire (GHQ) measure. Von Scheve et al. (2013) however note that the time path of adaptation to unemployment differs according to the (single-item) well-being measure in SOEP data for 2007-2012. The effect of unemployment on anxiety and happiness (reported for the last four weeks) lasts for only one year. There is no impact effect for anger, but this rises with unemployment duration. Last, there is no adaptation in terms of sadness, nor in terms of life satisfaction. Finally, Luhmann et al. (2012) carry out meta-analyses, and find different adaptation effects in affective well-being and life satisfaction. However, the information revealed to date has been somewhat scattershot, and many questions remain open: For example, is there evidence of adaptation of the kind discussed in Sections 2 and 3 when we consider eudaimonia as the measure of well-being?

\subsection{Resilience}

Regression analysis produces conditional means, which reveal the average estimated effect over the population of interest. However, the size of this effect may differ widely between different groups of individuals. In terms of the effect of unemployment, for example, we might want to know which groups are most affected in well-being terms, and if some groups 
of individuals bounce back faster than do others. We can either make progress here by defining a priori groups who we think will be affected differently (and some of the analyses above have looked at separate effects for men and women), or we could let the data decide which individual to assign to which group in latent growth mixture models to identify multiple trajectories of subjective well-being in response to life events (as in Mancini et al., 2011).

Yap et al. (2014) suggest that resilience is related to personality traits in BHPS. Etilé et al. (2014) use HILDA data and a latent-class model to split individuals into three different resilience groups. As in Yap et al. (2014), resilience is related to personality traits (high internal locus of control and low levels of neuroticism). Etilé et al. (2014) also show that resilience is related to both current outcome variables (good health, male, well-educated) and those from childhood (being raised with an employed father and a stay-at-home mother). Powdthavee (2014) also considers resilience as a function of childhood characteristics.

As well as being of academic interest, the analysis of the distribution of resilience is of policy importance, as it would help to show us who needs help more, and in which circumstances.

\subsection{Does adaptation explain the Easterlin Paradox?}

Adaptation is a fascinating area of study. In this chapter, I motivated its analysis via its potential to explain the Easterlin Paradox. As noted in the Introduction, there are two parts to this paradox: a positive cross-section elasticity between income and subjective well-being, and a much smaller or zero time-series elasticity between the same two variables.

Adaptation to income can certainly explain the second part of the paradox: there will be no long-run well-being return to higher income if we get used to it. But what about the first part of the paradox? If we all adapt to higher incomes, then surely the rich should end up being just as happy as the poor. Yet the data suggest that the rich are systematically happier than the poor. $^{16}$

Of course it does take some time for adaptation to operate. In the short run, individuals are

\footnotetext{
${ }^{16}$ It could be countered that the rich have more positive values of the elements of the $\underline{X}$ vector in equation (1), so that they have higher set-point well-being. This may sound reasonable. But then we would expect increasing GDP per capita over time to go hand-in-hand with higher average happiness, as the average $\underline{X}$ values in the economy would then improve over time as well.
} 
happier with higher incomes, even if they will fully adapt to them in the long run: only recent changes in income affect well-being. As such, for the richer to report higher subjective wellbeing scores than do the poorer, the rich must have enjoyed more positive recent income gains than did the poor. In other words, adaptation can only explain the Easterlin Paradox when there is rising income inequality. And this has to be a certain type of rising income inequality: the Easterlin Paradox would not be explained by rising inequality where the poor were getting poorer, but instead requires that this inequality results from the rich becoming richer.

Clark et al. (2008) noted that, under adaptation, "the only way to achieve permanently greater happiness is to have continually rising income", but did not make the link to the cross-section relationship between income and happiness. While income inequality has indeed been rising in recent years in many countries, this has not been the case for all countries and all time periods for which the flat time-series relationship has been observed. I believe that this somewhat undermines the case that can be made for adaptation to income as an explanation for the Easterlin Paradox.

\section{Conclusion}

While adaptation occurs in many domains of economic and social life, it is not inevitable. In particular, we seem to adapt less, or not at all, to a certain number of negative events: unemployment, disability and poverty. Policy that aimed to increase well-being would want us to bounce back quickly from bad events, but not from good events. Some recent work has started to ask which kinds of individuals can indeed recover (in terms of subjective wellbeing) more quickly from negative shocks (or enjoy the positive shocks longer). This resilience has been related to both adult personality and childhood circumstances, providing a means via which policy can potentially produce more resilient adults.

A considerable amount of research has suggested that income rises do not produce lasting effects on well-being. Adaptation to income has been suggested as one of the two behavioural explanations of the Easterlin Paradox (the other being social comparisons). While I believe that there is adaptation to income (at least in rich countries), questions remain about whether adaptation is a good explanation of the paradox. The problem is that under adaptation the rich can only be happier than the poor if they receive more positive income shocks than do the 
poor. For adaptation to explain the Easterlin Paradox, income inequality must systematically rise. This has been true in some countries in some periods, but not all countries in all periods. 
Figure 1. Happiness Adaptation following an Income Shock

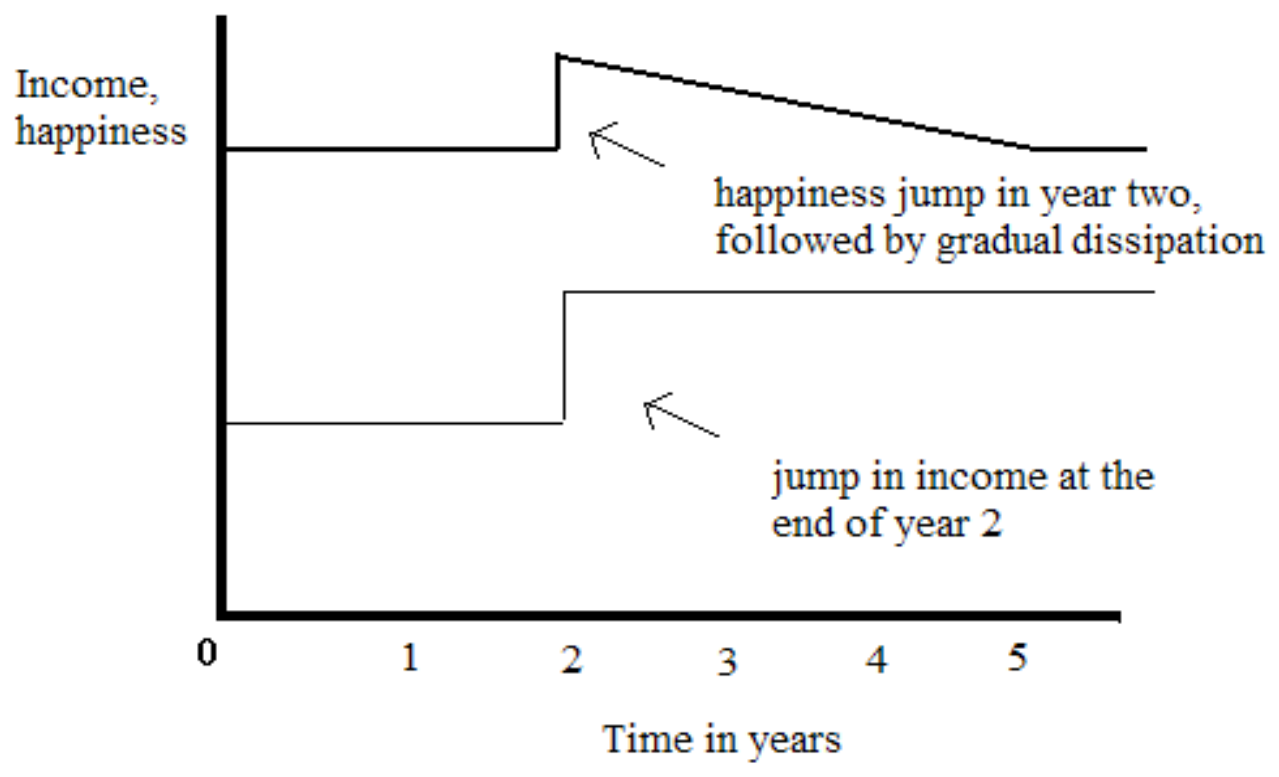

Note: Reproduced from Clark et al. (2008) 
Figure 2. The Time Profile of Life Satisfaction and Life and Labour Market Events: BHPS
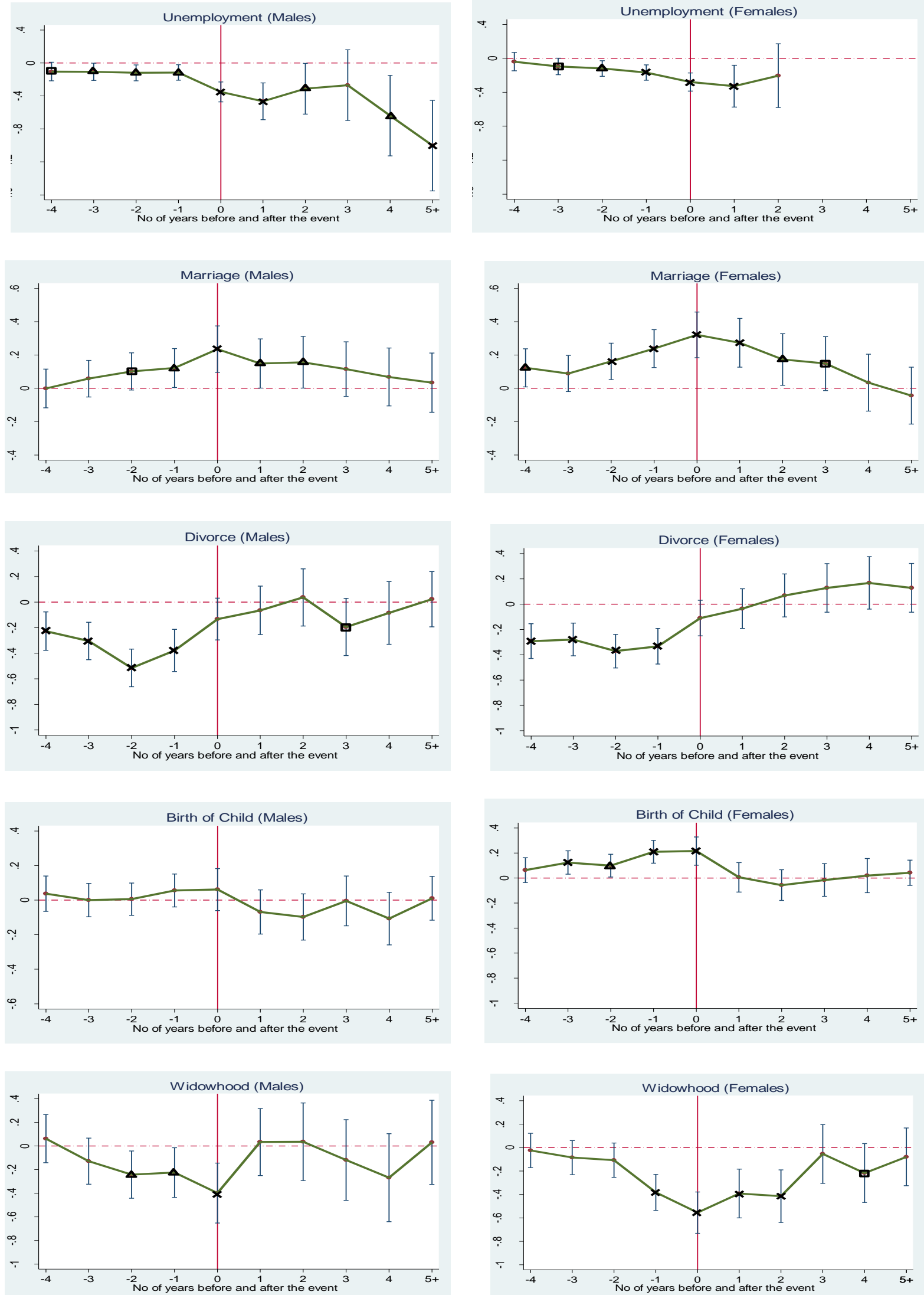

Notes: X, $\Delta$ and $\square$ denote significance at the one, five and ten per cent levels respectively; the error bars represent the 95 -percent confidence intervals. The analysis here concerns people who became unemployed (for example) at time zero and who stay unemployed over the period in question. The change in life satisfaction between times $t+1$ and $t+2$ is the average well-being (conditional on the other right-hand side variables) of individuals who are unemployed at $t+1$ and remain unemployed at $t+2$. Source: Clark and Georgellis (2013). 
Figure 3. Well-being Profiles over Time following Entry into Unemployment at Time $\tau$

A) Permanently-Falling

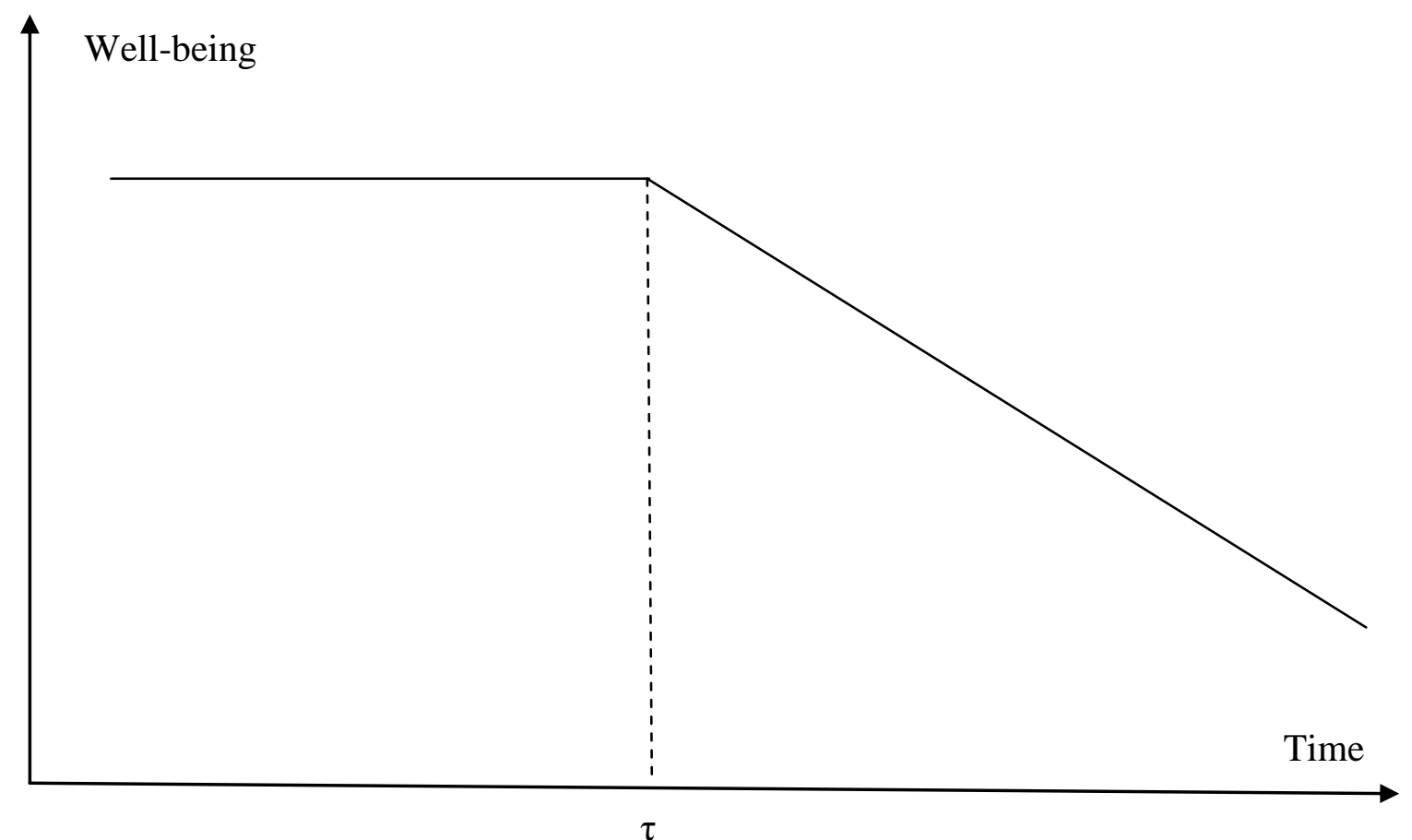


B) Step Function

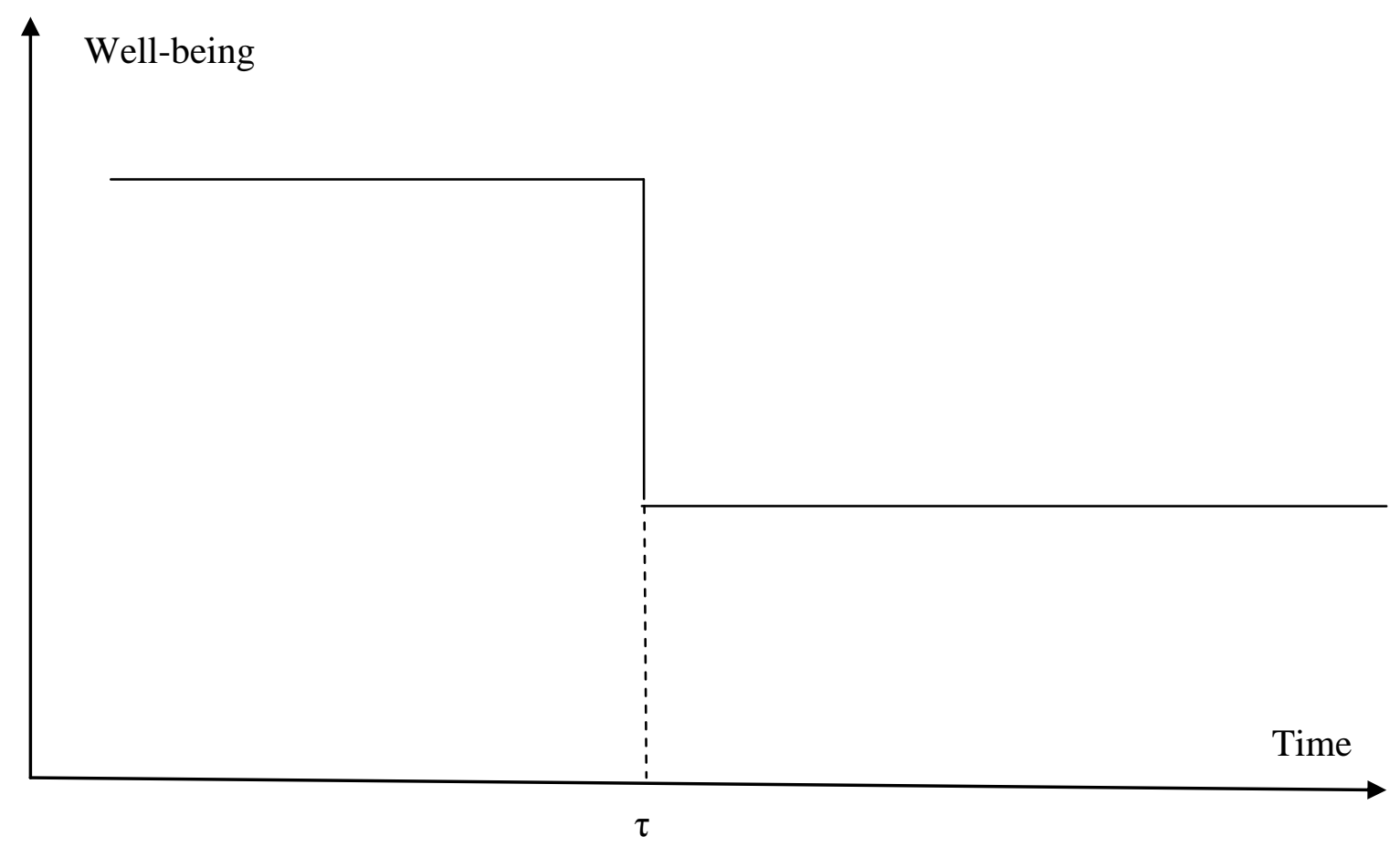

C) Adaptation

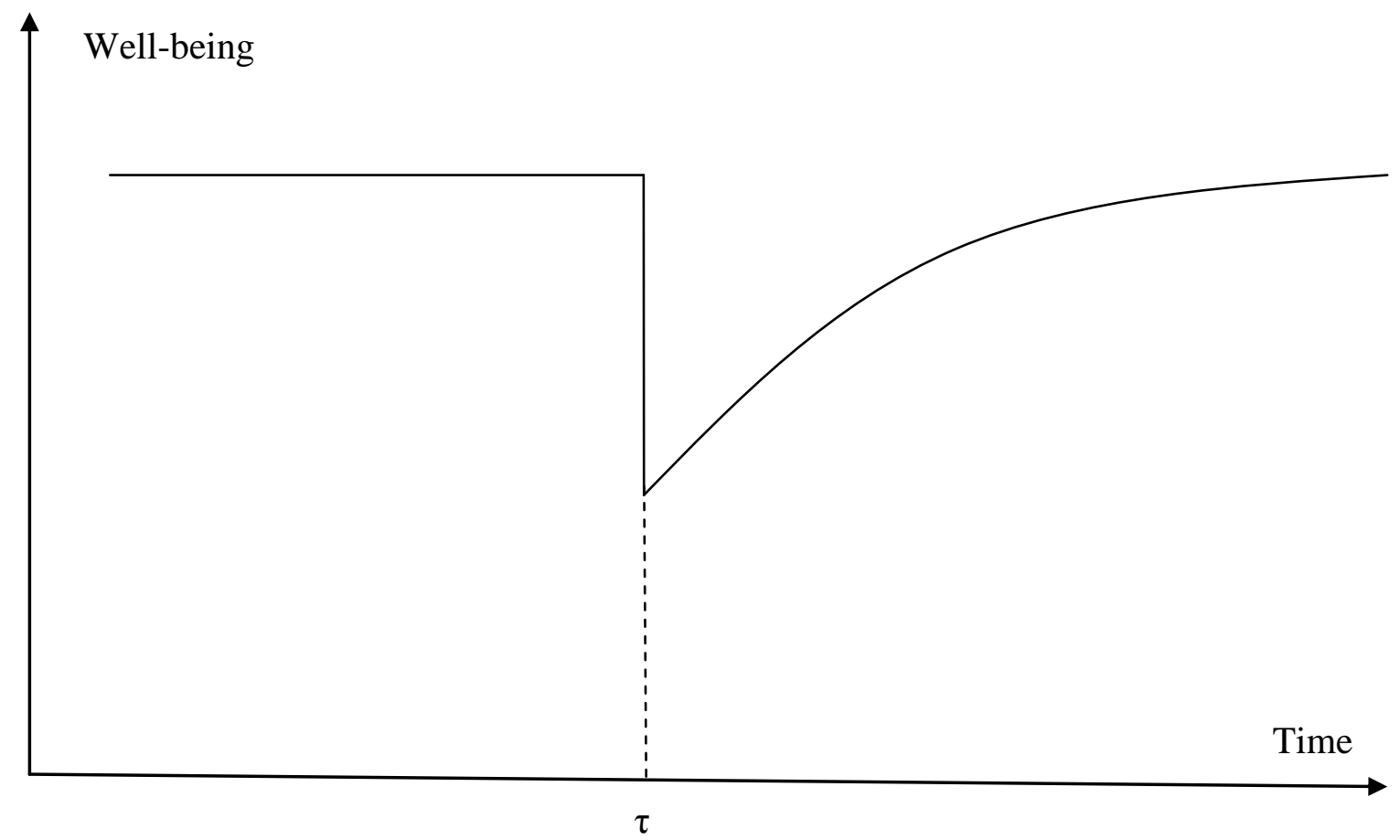




\section{References}

Anusic, I., Yap, S., and Lucas, R. (2014). "Testing Set-Point Theory in a Swiss National Sample: Reaction and Adaptation to Major Life Events". Social Indicators Research, 119, $1265-1288$.

Apouey, B., and Clark, A.E. (2015). "Winning Big but Feeling No Better? The Effect of Lottery Prizes on Physical and Mental Health". Health Economics, forthcoming.

Barazzetta, M. (2014). "Adaptation to treatment. Evidence from a RCT in Uganda". University of Nottingham, mimeo.

Bartolini, S., Bilancini, E., and Sarracino, F. (2013). "Predicting the Trend of Well-Being in Germany: How Much Do Comparisons, Adaptation and Sociability Matter?" Social Indicators Research, 114, 169-191.

Blekesaune, M. (2008). "Partnership Transitions and Mental Distress: Investigating Temporal Order". Journal of Marriage and Family, 70, 879-890.

Brickman, P., D., C., and Janoff-Bulman, R. (1978). "Lottery winners and accident victims: Is happiness relative?" Journal of Personality and Social Psychology, 36, 917-927.

Burchardt, T. (2005). "Are One Man's Rags Another Man's Riches? Identifying Adaptive Preferences Using Panel Data". Social Indicators Research, 74, 57-102.

Burchell, B. (2011). "A Temporal Comparison of the Effects of Unemployment and Job Insecurity on Wellbeing". Sociological Research Online, 16, Article 9.

Clark, A.E. (1999). "Are Wages Habit-Forming? Evidence from Micro Data". Journal of Economic Behavior and Organization, 39, 179-200.

Clark, A.E. (2015). "Is Happiness the Best Measure of Well-Being?" In M. Adler and M. Fleurbaey (Eds.), Oxford Handbook of Well-Being and Public Policy. Oxford: Oxford University Press.

Clark, A.E., D’Ambrosio, C. and Ghislandi, S. (2014a). "Adaptation to Poverty in Long-Run Panel Data" PSE, mimeo.

Clark, A.E., Diener, E., Georgellis, Y., and Lucas, R. (2008). "Lags and Leads in Life Satisfaction: A Test of the Baseline Hypothesis". Economic Journal, 118, F222-F243.

Clark, A.E., Flèche, S., and Senik, C. (2014b). "The Great Happiness Moderation". In A.E. Clark and C. Senik (Eds.), Happiness and Economic Growth: Lessons from Developing Countries. Oxford: Oxford University Press. 
Clark, A.E., Frijters, P., and Shields, M. (2008). "Relative Income, Happiness and Utility: An Explanation for the Easterlin Paradox and Other Puzzles". Journal of Economic Literature, 46, 95-144.

Clark, A.E., and Georgellis, Y. (2013). "Back to Baseline in Britain: Adaptation in the BHPS". Economica, 80, 496-512.

Clark, A.E., and Oswald, A.J. (1994). "Unhappiness and Unemployment". Economic Journal, 104, 648-659.

Clark, A.E., and Senik, C. (2010). "Who compares to whom? The anatomy of income comparisons in Europe". Economic Journal, 120, 573-594.

Clark, A.E., and Uglanova, E. (2012). "Adaptation in the East: Does Context Matter?" PSE, mimeo.

Cole, R., Shakespeare, V., Shakespeare, P., and Hobby, J. (1994). "Measuring outcome in low-priority plastic surgery patients using Quality of Life indices". British Journal of Plastic Surgery, 47, 117-121.

Di Tella, R., Haisken-De New, J., and MacCulloch, R. (2010). "Happiness adaptation to income and to status in an individual panel". Journal of Economic Behavior \& Organization, 76, 834-852.

Di Tella, R., MacCulloch, R.J., and Oswald, A.J. (2003). "The Macroeconomics of Happiness". Review of Economics and Statistics, 85, 809-827.

Dyrdal, G., and Lucas, R. (2013). "Reaction and Adaptation to the Birth of a Child: A CoupleLevel Analysis". Developmental Psychology, 49, 749-761.

Easterlin, R.A. (1995). "Will Raising the Incomes of All Increase the Happiness of All?" Journal of Economic Behavior and Organization, 27, 35-47.

Etilé, F., Frijters, P., Johnston, D., and Shields, M. (2014). "Mental health resilience: which Childhood Circumstances matter?" Paris School of Economics, mimeo.

Flèche, S. (2014). "Local Autonomy and Residents' Wellbeing: Evidence from Swiss Reforms". PSE, mimeo.

Frank, R.H., and Hutchens, R.M. (1993). "Wages, Seniority, and the Demand for Rising Consumption Profiles". Journal of Economic Behavior and Organization, 21, 251-276.

Frijters, P., Johnston, D., and Shields, M. (2011). "Happiness Dynamics with Quarterly Life Event Data". Scandinavian Journal of Economics, 113, 190-211.

Gardner, J., and Oswald, A.J. (2007). "Money and Mental Wellbeing: A Longitudinal Study 
of Medium-Sized Lottery Wins". Journal of Health Economics, 26, 49-60.

Graham, C., Higuera, L., and Lora, E. (2011). "Which health conditions cause the most unhappiness?" Health Economics, 20, 1431-144.

Grund, C., and Sliwka, D. (2007). "Reference-Dependent Preferences and the Impact of Wage Increases on Job Satisfaction: Theory and Evidence". Journal of Institutional and Theoretical Economics, 163, 313-335.

Hanglberger, D., and Merz, J. (2011). "Are Self-Employed Really Happier Than Employees? An Approach Modelling Adaptation and Anticipation Effects to Self-Employment and General Job Changes". IZA Discussion Paper 5629.

Hotz, V.J., Kydland, F.E., and Sedlacek, G.L. (1988). "Intertemporal Preferences and Labor Supply". Econometrica, 56, 335-360.

Inglehart, R., and Rabier, J.R. (1986). "Aspirations Adapt to Situations - But Why Are the Belgians so Much Happier than the French? A Cross-Cultural Analysis of the Subjective Quality of Life". In F.M. Andrews (Ed.), Research on the Quality of Life. Ann Arbor: Institute for Social Research University of Michigan.

Laporte, A., and Windmeijer, F. (2005). "Estimation of panel data models with binary indicators when treatment effects are not constant over time". Economics Letters, 88, 389-396.

Layard, R. (2005). Happiness: Lessons from a New Science. London: Penguin.

Loewenstein, G., and Sicherman, N. (1991). "Do Workers Prefer Increasing Wage Profiles?" Journal of Labor Economics, 9, 67-84.

Lucas, R. (2007). "Long-term disability is associated with lasting changes in subjective well being: Evidence from two nationally representative longitudinal studies". Journal of Personality and Social Psychology, 92, 717-730.

Lucas, R., Clark, A.E., Georgellis, Y., and Diener, E. (2003). "Re-Examining Adaptation and the Setpoint Model of Happiness: Reaction to Changes in Marital Status". Journal of Personality and Social Psychology, 84, 527-539.

Lucas, R., Clark, A.E., Georgellis, Y., and Diener, E. (2004). "Unemployment Alters the SetPoint for Life Satisfaction". Psychological Science, 15, 8-13.

Luhmann, M., Hofmann, W., Eid, M., and Lucas, R. (2012). "Subjective well-being and adaptation to life events: A meta-analysis". Journal of Personality and Social Psychology, 102, 592-615. 
Lyubomirsky, S. (2011). "Hedonic Adaptation to Positive and Negative Experiences". In S. Folkman (Ed.), The Oxford Handbook of Stress, Health and Coping. Oxford: Oxford University Press.

Mancini, A., Bonanno, G., and Clark, A.E. (2011). "Stepping Off the Hedonic Treadmill: Individual Differences in Response to Major Life Events". Journal of Individual Differences, 32, 144-152.

Margraf, J., Meyer, A., and Lavallee, K. (2013). "Well-Being From the Knife? Psychological Effects of Aesthetic Surgery". Clinical Psychological Science, 1, 239-252.

Myrskyla, M., and Margolis, R. (2014). "Happiness: Before and After the Kids". Demography, 51, 1843-1866.

Nowok B, van Ham M, Findlay A M, and Gayle V. (2013), "Does migration make you happy? A longitudinal study of internal migration and subjective well-being" Environment and Planning A, 45, 986-1002.

Oesch, D., and Lipps, O. (2013). "Does Unemployment Hurt Less if There is More of it Around? A Panel Analysis of Life Satisfaction in Germany and Switzerland". European Sociological Review, 29, 955-967.

Oswald, A.J., and Powdthavee, N. (2008). "Does happiness adapt? A longitudinal study of disability with implications for economists and judges". Journal of Public Economics, 92, 1061-1077.

Powdthavee, N. (2011). "Anticipation, Free-Rider Problem, and Adaptation to Trade Union: Re-examining the Curious Case of Dissatisfied Union Members". Industrial and Labor Relations Review, 64, 1000-1019.

Powdthavee, N. (2014). "What childhood characteristics predict psychological resilience to economic shocks in adulthood?" Journal of Economic Psychology, 45, 84-101.

Qari, S. (2014). "Marriage, adaptation and happiness: are there long-lasting gains to marriage?" Journal of Behavioral and Experimental Economics, 50, 29-39.

Riis, J., Loewenstein, G., Baron, J., Jepson, C., Fagerlin, A., and Ubel, P. (2005). "Ignorance of Hedonic Adaptation to Hemodialysis: A Study Using Ecological Momentary Assessment". Journal of Experimental Psychology: General, 134, 3-9.

Rudolf, R., and Kang, S.-J. (2015). "Lags and Leads in (Korean) Life Satisfaction: When Gender Matters". Feminist Economics, forthcoming.

Stevenson, B., and Wolfers, J. (2008). "Economic Growth and Subjective Well-Being: 
Reassessing the Easterlin Paradox". Brookings Papers on Economic Activity, Spring, 1102.

Stutzer, A., and Frey, B.S. (2006). "Does Marriage Make People Happy, Or Do Happy People Get Married?" Journal of Socio-Economics, 35, 326-347.

Van Praag, B.M. (1971). "The Welfare Function of Income in Belgium: An Empirical Investigation". European Economic Review, 2, 337-369.

Van Praag, B., and Frijters, P. (1999). "The Measurement of Welfare and Well-Being: The Leyden Approach". In D. Kahneman, E. Diener, and N. Schwartz (Eds.), Well-being : the foundations of hedonic psychology. New York: Russell Sage.

Verhaest, D., and Omey, E. (2009). "Objective over-education and worker well-being: A shadow price approach". Journal of Economic Psychology, 30, 469-481.

Von Scheve, C., Esche, F., and Schupp, J. (2013). "The Emotional Timeline of Unemployment: Anticipation, Reaction, and Adaptation". IZA, DP No. 7654.

Weinzierl, M. (2005). "Estimating a Relative Utility Function". Harvard University, mimeo.

Winkelmann, L., and Winkelmann, R. (1998). "Why Are the Unemployed So Unhappy? Evidence from Panel Data". Economica, 65, 1-15.

Wunder, C. (2009). "Adaptation to income over time: A weak point of subjective well-being". Schmollers Jahrbuch, 129, 269-281.

Vendrik, M. (2013). "Adaptation, anticipation and social interaction in happiness: An integrated error-correction approach". Journal of Public Economics, 105, 131-149.

Yap, S., Anusic, I., and Lucas, R. (2012). "Does personality moderate reaction and adaptation to major life events? Evidence from the British Household Panel Survey". Journal of Research in Personality, 46, 477-488. 